\title{
CHERNOBYL - A CATÁSTROFE
}

Djmes Yoshikazu de Lima SUGUIMOTO ${ }^{1}$

Maria Augusta de CASTILHO

${ }^{1}$ Graduado em História - E-mail: djmessuguimoto@ hotmail.com

${ }^{2}$ Doutorado em História. Universidade Católica Dom Bosco - Email: m.a.castilho@ @erra.com.br

Recebido em: 25/05/2014 - Aprovado em: 15/09/2014 - Disponibilizado em: 15/12/2014

RESUMO: Na madrugada de 26 de abril de 1986 o pior acidente nuclear para fins pacíficos aconteceu na extinta URSS. O acidente liberou cerca de 50 toneladas de produtos radioativos provenientes da fissão, pegando carona em nuvens que praticamente viajou em toda Europa chegando até a costa leste dos EUA. Por meio das chuvas e outros fatores climáticos foram depositados produtos como o césio-137 que tem sua meia-vida de 30 anos, o que levará séculos para que alguns locais possam ser habitados novamente. As regiões que receberam as maiores taxas de contaminação foram a Ucrânia país que abrigava o reator, a Rússia e a Belarus somando 145 mil quilômetros quadrados que não pode receber nenhum morador, lavoura ou animais. No momento do acidente quase sete milhões de pessoas residia próxima à usina, sendo que 350 mil foram expulsas dos seus lares levando apenas a roupa do corpo. As vítimas da catástrofe estão sendo esquecidos pela história como os moradores e os liquidadores, termo produzido na época para trabalhadores de várias áreas que fizeram a limpeza da zona de exclusão. A pesquisa se valeu de textos especializados, principalmente em fontes oficiais e órgãos não governamentais reconhecidos internacionalmente, por sua luta contra a instalação e a manutenção de usinas e armas nucleares. Outras fontes tais como livros e artigos também serviram de base para se confrontar com os documentos (oficiais ou não), possibilitando revelar a micro-história e os motivos da memória e esquecimento de fato tão importante.

Palavras-chave: Chernobyl. Catástrofe nuclear. Césio-137. Território. Vítimas.

\section{CHERNOBYL - CATASTROPHE}

\begin{abstract}
At dawn on April 26, 1986 the worst nuclear accident happened for peaceful purposes in the former URSS. The accident released about 50 tons of radioactive fission products from, piggybacking on clouds that virtually traveled throughout Europe coming to the EUA east coast. Through rainfall and other climatic factors products such as cesium -137 has a half -life of 30 years, which will take centuries to some areas may be inhabited again were deposited. The regions receiving the highest contamination rates were Ukraine country that housed the reactor, Russia and Belarus totaling 145 square kilometers that can not receive any resident, farming or animals. At the time of the accident nearly seven million people lived close to the plant, and 350,000 were expelled from their homes taking only the clothes on their backs. The disaster victims are being forgotten by history as locals and liquidators, produced in term time for workers in various areas that have cleaned the exclusion zone. The research made use of specialized texts, mostly on official sources and non-governmental agencies internationally recognized for his fight against the installation and maintenance of power plants and nuclear weapons. Other sources such as books and articles were also the basis for confronting the documents (official or not), allowing reveal the micro - history and the reasons for memory and forgetting in fact so important.
\end{abstract}

Keywords: Chernobyl. Nuclear catastrophe. Cesium-137. Territory. Victims.

\section{Introdução}

A usina nuclear Vladimir Lênin está localizada a cerca de $20 \mathrm{~km}$ da cidade de
Chernobyl, e cerca de $110 \mathrm{~km}$ de Kiev capital da Ucrânia e a $4 \mathrm{~km}$ da cidade de Pripryat. A instalação da usina foi iniciada em 1970 e em 1983 foi entregue $\mathrm{o}$ reator $\mathrm{n}^{\mathrm{o}} 4$ onde 
aconteceu o acidente. Ainda existiam dois reatores em construção no momento da tragédia, mas os dois últimos complexos só tiveram suas obras paralisadas após três anos. Em dezembro de 2000 foram definitivamente desativados todos os reatores, mas ainda hoje existem pessoas que trabalham em Chernobyl, tais como: militares, funcionários da usina que atuam no controle da radiação e na administração.

\section{Finalidades da usina nuclear}

A construção desta usina teve como estratégia sua localização geográfica para beneficiar a União Soviética, e além de oferecer energia para cidades industriais e residenciais. A fabricação de bombas nucleares era o aspecto mais sombrio da usina, já que o contexto geopolítico neste período tornava indispensável à produção e a corrida armamentista entre duas potências: EUA e URSS. Na segunda guerra mundial os EUA detonaram duas bombas atômicas nas cidades japonesas de: Hiroshima e Nagasaki. Essa arma fez com que vários cientistas soviéticos voltassem seu trabalho para a força do átomo, esse esforço representava o orgulho tecnológico que uma sociedade socialista podia criar. Em 1942 a URSS deu início ao programa nuclear soviético, com seus engenheiros apelidados de especialistas vermelhos pelos engenheiros ocidentais. Esses cientistas soviéticos conheciam e dominavam o desenvolvimento e construção de bombas nucleares, mas a questão das usinas estava atrasada em comparação ao ocidente, já que a preocupação naquele momento era a produção do plutônio. A construção de uma bomba nuclear que os soviéticos desejavam tinha como principal combustível o plutônio, que pode ser produzido apenas artificialmente.

Era necessária a produção em grande escala para desenvolver reatores específicos para fabricação deste elemento químico. Esse processo gera energia térmica, antes de se pensar em usinas para produção de energia elétrica esse calor resultante da transformação de urânio em plutônio causava dor de cabeça aos pesquisadores. "A quantidade imensa de calor que produziam era tida como inconveniente pelos projetistas" (HAWKES et al., 1986, p. 36). Os locais de produção eram semelhantes às usinas nucleares, existindo barras de contenção para controlar nêutrons, água ou gás, chamados de refrigerante, para a refrigeração que se torna vapor, com os mesmos princípios de usinas termoelétricas que utilizam o vapor para girar turbinas e produzir energia elétrica, com algumas vantagens, e uma delas era em quantidade de combustível utilizado. "A energia contida em um quilo de urânio utilizado em um reator, quando liberada, equivale à fornecida pela quantidade de 3.000 toneladas de carvão em usina convencional" (HAWKES et al., 1986, p. 34). A produção de energia foi uma consequência das pesquisas para desenvolvimento de armas 
nucleares, e isso aconteceu em todos os países que fizeram instalação e tais usinas.

\section{Visão ocidental}

A forma com que este projeto era visto pelo ocidente refere-se a mentalidade discriminatória pelo regime adotado na URSS. Alguns pesquisadores como Michele Lee e Oliver MacDonald examinaram a engenharia empregada na usina de Chernobyl. Em entrevista concedida para revista New Left Review de maio/junho de 1986 esses pesquisadores não atacam a usina ou o projeto, mas explicam de forma racional vários pontos que naquele momento ainda era uma dúvida: da evolução do reator PWR para o modelo em questão, sendo bastante sofisticada exemplificando a eficiência individual de cada tubo que armazena o combustível, de como é fácil trabalhar com os bastões sendo retirados individualmente e os motivos, na visão deles, para construção da usina (MEDVEDEV, 1987).

Examinando em fontes publicadas no período, que para outros pesquisadores do assunto tudo não passou de mais um erro grotesco do sistema comunista. É certo que a utilização do reator RBMK "Reactor Bolshoy Moshchnosty Kanalny" (reator de canaletas de alta potência) devia-se a vários fatores, tanto econômico, político e militar, mas sem dúvida os especialistas vermelhos eram capazes de aplicar os conhecimentos matemáticos, técnicos e científicos na criação de usinas assim como os engenheiros ocidentais.

Produzir plutônio era um orgulho para a engenharia da União Soviética, sendo totalmente projetada pelos especialistas vermelhos e sendo alimentado de urânio com menor índice de enriquecimento.

Para reduzir os riscos com o urânio, a
maioria dos reatores ocidentais esfriados
com água usa urânio altamente
enriquecido, a taxa de 3,5\%. Para
economizar, os russos planejaram a usina
de Chernobyl com reatores onde o urânio
está enriquecido a $1,8 \%$ e é guardado
dentro de blocos de grafite. O grafite é
colocado em torno do urânio para manter
a eficiência da operação (REVISTA
VEJA, 1986, p. 39).

A facilidade na troca do combustível feita por um guindaste sobre trilho também foi fator importante para utilização deste modelo de reator, já que não era necessário o desligamento total do reator, a queima não acontecia de forma regular. O núcleo sofria maior deteorização se comparadas com as extremidades, então era necessário fazer várias trocas, tornando este ponto do sistema desfavorável. À medida que substituía as varetas era necessário fazer perfurações enfraquecendo a tampa do reator. O tamanho do reator e a ponte móvel impedia a construção de um vasilhame metálico de contenção que cobrisse toda a estrutura (GROSS, 1987).

A única proteção era uma tampa de cimento que pesava em torno de 700 toneladas Ainda assim esse modelo foi 
implementado em outros locais da URSS, o que trazia a instabilidade do reator era ser operado em baixa potência e os engenheiros soviéticos não tinham conhecimento até o acidente.

\section{0 acidente}

A usina tinha recebido ordens do comitê estatal para uso da energia atômica e para fazer manutenção de rotina no reator $n^{\circ} 4$ no dia 25 de abril de 1986. Aproveitando a ocasião seriam realizados testes sobre a capacidade de refrigeração na falta de energia. As usinas nucleares não apenas produzem energia, mas também consomem para acionar as bombas responsáveis pela circulação do refrigerante que vai para o núcleo e sistemas auxiliares. Se uma usina está acima de $20 \%$ de produção ela própria se mantém, quando está abaixo deste valor precisa de energia externa (ESTEVES, 2013).

Caso falte energia o sistema de segurança entra em ação ligando os geradores de emergência movidos a diesel. Não é explícito, mas é certo que o motivo maior do teste na refrigeração era o medo de um ataque como ocorreu na central nuclear no Iraque em 1981 pelos israelenses.

A primeira parada programada da unidade 4 seria aproveitada para um experimento que consistia em reduzir a potência ao mínimo e desligar o reator junto com o corte da energia externa, simulando um blecaute (DALAVIA, 2014, p. 2).
O ponto principal era saber se as turbinas conseguiriam alimentar as bombas de refrigeração do núcleo por inércia no tempo mínimo de 40 segundos até que as bombas a diesel fossem ligadas. A melhor maneira de fazer este procedimento seria o desligamento do reator, pois o mesmo tinha que ser operado por controles manuais. Em circunstâncias normais o sistema automático não tinha a programação para execução de tal manobra. Os operadores sabiam que uma parada total levaria dias para religar completamente o reator, devido ao fenômeno de envenenamento por xenônio 135 , essa atitude auxiliou a gerar o acidente.

$\mathrm{O}$ experimento que estava prestes a ser feito foi realizado no pior momento, pois vários pontos cruciais que levariam a instabilidade estavam prontos para entrar em choque, tais como: todos os sistemas de segurança foram desligados, a barra de combustível estava em seu ciclo final, neste momento a falta de resfriamento ficou mais perigosa já que o produto da fissão no final de ciclo gerou uma quantidade maior de calor e ficou altamente instável. "O período final do combustível é onde tem maior acúmulo de resíduo nuclear, resultado da fissão do urânio, com isso o risco de vazamento também aumentou" (DALAVIA, 2014, p. 2).

Inicialmente os testes estavam programados para começar à $1 \mathrm{~h}$ da madrugada do dia 25 de 1983. Às 14h houve o que se pode considerar como um dos pontos cruciais no acidente, o desligamento do 
sistema de resfriamento de emergência o que evitava seu funcionamento durante os testes. No mesmo momento houve um aumento na demanda de energia adiando o teste para o próximo turno. Às 00h houve a troca dos 256 funcionários para grupo da noite que assumiria a usina, o sistema de emergência continuava desativado. A potência na madrugada do dia 25 estava em 3.200MWth e foi reduzida até $1.600 \mathrm{MWth}$. Manteve-se esta situação até as $00 \mathrm{~h} 005 \mathrm{~min}$ do dia 26 , ocasião em que foi reduzida para 720MWth e continuava diminuindo. Segundo o relatório para execução dos procedimentos a potência segura do reator para execução seria de $700 \mathrm{MWth}$ a $1.000 \mathrm{MWth}$. Por ordem do engenheiro supervisor Anatoly Dyatlov Stepanovich responsável pelo procedimento o reator teria sua potência diminuída até 200MWth para dar inicio aos testes. O operador responsável pela potência não conseguiu operar o sistema com a destreza necessária para balancear a força do reator, caindo para 30MWth, nesse momento começou o processo de envenenamento por xenônio 135.

Os produtos de fissão produzidos durante a operação de reator figura o xenônio 135 , um gás que apresenta uma alta taxa de absorção de nêutrons. Quando o reator esta em operação total há nêutrons suficientes para que essa absorção não represente nenhum problema, mas quando ele funciona a baixa potência ou é completamente desativado, o acumulo de xenônio 135 fica insignificante. Depois da desativação total, o iodo 135 presente no núcleo continua a sofrer decaimento, produzindo mais xenônio 135, que vai se acumulando. Em consequência disso, o reator, da mesma forma que um carro afogado, só pode ser ligado depois que se tiver passado tempo suficiente para que o xenônio 135 decaia (HAWKES et al., 1986, p.79).

O reator não respondia de forma eficiente e o controlador não conseguia elevar a potência devido ao envenenamento, pois a atitude feita contrariava todas as normas de segurança. O reator possuía um total de 211 barras de controle, mas o máximo de barras que poderia ser removida seria de 181 , porém foram deixadas pelo operador apenas 6 . “Optou-se pela remoção das barras de controle, aumentando a potência do reator entrando num regime de funcionamento instável, com risco de sofrer elevações incontroláveis de potência" (ESTEVES, 2013).

Normalmente o reator funciona com quatro bombas de refrigeração, o que é suficiente para manter a pressão de água e vapor adequada dentro dos tubos, sendo extremamente importante devido à condição do tipo de reator. Neste dia as quatro bombas estavam em funcionamento e foram adicionadas mais duas; posteriormente foi ligada ao sistema mais duas bombas ficando com um total de oito.

Estava criada, no entanto, uma situação irregular, com oito bombas funcionando e o reator em potência de apenas $200 \mathrm{MW}$, e não de 500MW conforme estabelecida no programa. [...] Como decorrência, a residência hidráulica do sistema de circulação (núcleo com os canais de combustível e as próprias bombas) atingiu um ponto sensivelmente menor do que o 
valor previsto para o funcionamento normal e seguro do reator. Como havia menos vapor - e, portanto, menos pressão - nos sistemas de circulação, o volume de água em circulação aumentou enormemente, até atingir 56.000 a $58.000 \mathrm{~m}^{3} / \mathrm{h}$. Trata-se de regime proibido, pois implica risco de danificação das bombas e produz vibrações nos principais sistemas de resfriamento (com ocorrência de cavitação), criando ainda uma fonte adicional de calor (GROSS, 1987, p. 32).

O fluxo de vapor no controlador caiu devido ao volume de água disparando os alarmes, ao invés da manobra ser interrompida e o reator desligado, o controlador desligou o alarme. A combinação de menos barra de controle com um fluxo maior de água e xenônio 135 no primeiro momento ajudou a manter o nível de nêutrons no núcleo, já que a água retém essa partícula. Quando o teste propriamente começou, foram fechadas as válvulas de entrada da turbina e a energia das bombas d'água foi desligada, diminuindo assim o fluxo de água no núcleo.

Às 1:23:04h foram fechadas as válvulas que controlam o fluxo de vapor para o turbo gerador $n^{\circ} 8$, iniciando-se assim run - down propriamente dito. Desligou-se ao mesmo tempo o sistema de proteção que entra automaticamente em operação quando o gerador funciona em condições irregulares (GROSS, 1987, p. 33).

O reator deixa a estagnação e começa o aumento na reação criando vapor devido à falta de água para manter refrigerado. O espaço entre as bolhas não consegue absorver os nêutrons, permitindo sua passagem gerando o processo em cadeia e dessa forma torna-se, a formação de vapor é incontrolável.
Os operadores ainda não tinham conhecimento do que estava acontecendo no núcleo, lembrando que todos os sistemas de segurança foram desativados, neste momento a última opção para evitar o desastre.

Quando foi percebido o que estava acontecendo, o chefe de turno ordena que fossem inseridas as barras, o operador aperta o botão AZ-5, responsável por inserir todas as barras de controle no núcleo. O calor no interior do reator era tão intenso que deformou as barras de combustível impedindo a passagem das barras de controle. Em uma medida desesperada as barras foram soltas dos motores que faziam a inserção. Todo o grafite que existia no núcleo fez com que a força armazenada nos combustíveis fosse amplificada, quando as barras de controle foram inseridas ao invés do reator reduzir, ele aumentou sua capacidade. "Com a inserção das barras, houve o deslocamento da água que refrigera os elementos combustíveis para dar lugar ao encamisamento e, no primeiro instante, houve uma subida brusca na potência ao invés do efeito desejado que era o de reduzir a potência” (ESTEVES, 2013).

Neste momento não existia nenhuma possibilidade de reversão da situação, o que estava por vir seria o fim do reator e o início do maior desastre nuclear para fins pacíficos do mundo. O nível de potência salta de $7 \%$ para $50 \%$ em apenas três segundos (HAWKES et al., 1986, p. 82).

$\mathrm{O}$ excesso de vapor fez com que todo o sistema começasse a vibrar, a força exercida 
no sistema era além do que o projeto podia suportar; a pressão acumulada fez com que um equipamento de 200 ton. caísse sobre o sistema de refrigeração agravando ainda mais o problema. Ouve-se um primeiro estrondo, era o vapor destruindo o reator, uma explosão hidráulica fazendo com que a tampa de contenção que pesava 700 t. fosse levantada, que na sua queda destruiu boa parte do prédio.

Os reatores de Leningrado não contam com vaso de contenção, nem com sistema de vaporização por canais e sistema alternativo de desativação, tais como os adotados na Inglaterra. Contudo, o problema mais importante parece ser o de projetar e demonstrar um sistema de contenção do núcleo que possa resistir à pressão do vapor no caso de rompimento dos tubos pressurizados (HAWKES et al., 1986, p. 85).

As matérias que existiam dentro do reator como o grafite e o zircalói, que em contato com a água e o calor extremo produziu hidrogênio e monóxido de carbono, ao entrar em contato com o oxigênio tornando-se explosivo. Após a explosão de vapor, o hidrogênio contido no reator inicia várias outras explosões. Tais explosões, incendiárias, inicialmente foram combatidas pela equipe de bombeiros (30 focos) e o grafite presente em grandes quantidades está superaquecido, tornando quase impossível o controle do incêndio pelos bombeiros que vão trabalhar no local. A explosão liberou toda a radioatividade contida no interior do reator, materiais como: plutônio, césio, estrôncio, urânio e grafite altamente contaminados foram ejetados para fora da usina.

Fontes divergem sobre a quantidade de material lançado para a atmosfera, uns calculam a liberação cerca de 50 ton. de produtos nucleares, outros assinalam 3 milhões de terabecqueréis, e outros consideram 10 vezes mais do que a bomba de Hiroshima.

O reator $n^{\circ} 4$ de Chernobyl estava com seu futuro selado, liberando radioatividade sem nenhum controle pelos próximos oito meses até que a limpeza e construção do sarcófago fossem finalizadas, tornando-se um problema ainda maior para a URSS.

\section{A cidade de Pripyat e os moradores}

A cidade de Pripyat foi fundada em quatro de fevereiro de 1970, principalmente para os trabalhadores da usina. A infraestrutura contava com casas, apartamentos, escola, hospitais, bibliotecas, cinemas, salas de espetáculos, locais para esporte, lojas, ferrovia e rodovia. Todos os trabalhadores da usina esforçavam-se ao máximo para permanecer na cidade, o medo de ser transferido para outros lugares sem a mesma estrutura forçava com que as decisões do partido ou dos engenheiros chefes fossem executadas sem alterações, ou questionamentos, o que se pode explicar em partes por que os operários não desistiram do teste na usina. 
Quando o acidente aconteceu sua população tinha cerca de 49.000 habitantes, segundo o documentário - O desastre de Chernobyl produzido pelo Discovery Chanel, que é reconhecido pela embaixada da Ucrânia no Brasil por meio de documento disponibilizado como fonte fidedigna. Tal documentário atesta que só após trinta horas do ocorrido as medidas de precaução foram tomadas para os habitantes, como a distribuição de pílulas de iodo e a evacuação em massa. O prazo para evacuação foi de duas horas, literalmente a população saiu com a roupa do corpo abandonado sua casa e vida naquela cidade. Segundo essa mesma fonte todas as pessoas foram evacuadas em apenas três horas e meia, sem nenhum tipo de pânico, ônibus levaram os primeiros refugiados atômicos da Europa. A evacuação aconteceu sem nenhum tipo de desespero, mas não foram sem recusa, uma vez que muitos moradores em alguns locais convocaram assembleias para evitar a saída das pessoas. Alguns idosos não acreditavam em um inimigo invisível, chegavam a esconder-se em porões e quando achados pelos militares ficaram aos prantos por ter que abandonar suas terras. A cidade de Chernobyl só foi evacuada no dia 27 , essa cidade era maior que Pripyat, a estratégia para levar as pessoas a um local com melhores condições foram as mesmas executadas nas primeiras cidades e vilas.

As cidades, vilas e casas rurais dentro da zona de exclusão nunca mais iriam receber nenhum habitante, tornando-se cidadesfantasmas que ainda hoje abriga objetos dos seus antigos moradores. Segundo o Greenpeace Brasil (2011) cerca de sete milhões de pessoas estavam em zonas contaminadas no período do acidente, e foi estimado que trezentos e cinquenta mil pessoas deixaram seus lares nas zonas mais contaminadas.

\section{Possíveis vítimas}

Por mais perturbador e absurdo que possa parecer, as informações oficiais sobre mortes no primeiro momento foi de apenas duas pessoas, posteriormente esse número foi alterado. Ainda hoje algumas fontes divergem sobre a contagem dos mortos, a Organização Mundial da Saúde (OMS) e fontes oficiais assinalam em um total de 59 mortes relacionadas diretamente ao acidente, outras fontes apontam 31 ou 33 pessoas.

As primeiras pessoas a morrerem no acidente foram alguns funcionários que trabalhavam no interior da usina, nem todos morreram imediatamente ou devido às altas doses de radiação, alguns ficaram presos, ou sofreram queimaduras em todo o corpo. As primeiras pessoas que não trabalhavam diretamente na usina foram os bombeiros que rapidamente atenderam o chamado. A explosão ejetou em todas as direções grafite em chamas altamente radioativos, que se tornou quase impossível à extinção das chamas com os métodos tradicionais. Todos 
os bombeiros receberam doses muito elevadas de radiação, o equipamento de proteção não era adequado para tal situação, a temperatura do local chegou a derreter a sola dos sapatos destes homens. Algumas horas depois foi solicitado o reforço, os que tentavam apagar o fogo começavam a mostrar os primeiros sintomas de contaminação, os primeiros bombeiros morreram imediatamente ou em alguns dias depois.

A limpeza do desastre ficou por conta dos liquidadores, um apelido dado às pessoas que trabalharam em qualquer função relacionada à limpeza e contenção da radiação. Esse termo está ligado a questão de "liquidar Chernobyl" ou "acabar com o problema”. Os liquidadores eram: engenheiros, reservistas, militares das forças armadas, bombeiros, civis, mineiros, trabalhadores de construção, médicos e policiais. Essas pessoas fizeram parte de uma operação gigantesca que envolvia a limpeza na zona de exclusão, caça aos animais contaminados, construção de um túnel embaixo do reator avariado para instalação do sistema de refrigeração, fiscalização dos limites, construção do sarcófago entre outras funções. Uma estimativa do contingente de pessoas foi de seiscentas mil, todas contaminadas de alguma forma sofrendo os efeitos até os dias de hoje. Essas pessoas ficaram fisicamente incapacitadas e seus auxílios constantemente são reduzidos, deixando sua situação ainda mais precária.
Outro grupo que esteve no centro do problema foi apelidado de biorobôs, jovens com a tarefa de limpar o telhado onde seria erguida a estrutura do sarcófago. Quando os engenheiros descobriram que o resto do telhado que resistiu a explosão estava cheio de grafite contaminado, decidiram jogar o lixo de volta para dentro do prédio, já que a estrutura cobriria tudo. Optou-se em utilizar robôs. Depois de algum tempo em funcionamento esse equipamento foi seriamente danificada devido ao alto grau de radioatividade que emanava do núcleo, a alternativa seria utilizar pessoas para fazer esse trabalho. Os homens selecionados para função tiveram que adaptar placas de chumbo ao seu corpo para minimizar os efeitos da contaminação, o trabalho tinha que ser rápido e só podiam permanecer no local por no máximo 40 segundos.

Esses homens sacrificaram suas vidas para evitar um desastre sem precedentes. Combateram o incêndio, diminuíram o nível de radioatividade, e limparam da melhor forma possível a zona de exclusão. Alguns homens não foram reconhecidos como liquidadores, foram excluídos dos méritos e da história, fizeram o trabalho que nem as máquinas suportavam. Foram os verdadeiros heróis que evitaram algo ainda pior e estão sendo esquecidos. 


\section{Como o mundo soube da tragédia}

A União Soviética escondeu o que estava acontecendo ao máximo. A Suécia foi o primeiro país que achou que havia algo errado, devido ao seu programa rígido de controle nas usinas, notaram que a poeira na roupa dos trabalhadores apresentava radioatividade muito acima do normal. Nesse momento todos os alarmes soaram e deixaram os suecos preocupados; medidas foram tomadas sem saber o que tinha acontecido, não estava no seu país mais sim no seu vizinho. Depois de uma extensa verificação percebeu-se que nada tinha acontecido nas suas usinas, voltaram suas dúvidas para os soviéticos. A Suécia tem em todo o território sensores que podem verificar qualquer variação na radioatividade, assim comunicaram à Casa Branca (EUA), que no primeiro momento não deu atenção ás informações afirmando que poderia ser gases que escaparam do subsolo devido aos testes. Os sensores sísmicos que foram instalados para verificar testes nucleares no subsolo não detectaram qualquer movimentação e os isótopos que estavam viajando junto com as nuvens apontavam que algo mais grave ocorrera.

Os soviéticos só assumiram que algo tinha acontecido dentro de suas fronteiras dois dias depois, enquanto isso, satélites espiões já vasculhavam para verificar o que tinha acontecido dentro da cortina de ferro. O mesmo documento cedido pela embaixada ucraniana reconhece que a nuvem com material tóxico fez seu passeio em praticamente toda a Europa, alcançando pontos do litoral leste dos EUA. Em outra fonte também é citado o tamanho da dimensão "[...] praticamente toda a Europa, parte da Ásia e, em menor escala, a América do Norte foram contaminadas pelos radionuclídeos liberados no acidente" (PASCHOA, 1987, p. 36).

Após alguns dias o líder Mikhail Gorbachev fez um pronunciamento revelando o que tinha acontecido. A ocasião inédita que marcou a história foi o pedido de auxílio que fez ao ocidente. Foi o próprio Gorbachev que convidou Hans Blix na época presidente da Agência Internacional de Energia Atômica (1981-1997), para inspecionar as consequências do desastre, sendo o primeiro ocidental designado para tal função. Para alguns o acidente em Chernobyl foi um golpe duro para URSS.

\section{Contaminados por radiação e esquecimento}

A contabilização das mortes que já aconteceram e ainda vão acontecer para a $\mathrm{OMS}$, chegou à casa de quatro mil vítimas. $\mathrm{O}$ curioso nos dados que são apresentados por este órgão internacional ligado as Nações Unidas é a forma branda que a pesquisa leva em conta a aceitabilidade das pessoas permanecerem em locais contaminados. Ela julga que cerca de cinco milhões de pessoas 
ainda residem em locais onde se deve tomar medidas defensivas para diminuir o nível de contaminação, e assume que essas pessoas estão recebendo algum tipo de radiação lentamente. $\mathrm{O}$ documento dá a entender que é aceitável o nível de radiação destes locais, por mais que as pessoas estão sendo envenenadas aos poucos.

Para Dupuy (2007), o modelo usado pelos pesquisadores e autoridades para definir o número de pessoas afetadas ou as mortes é um cálculo que analisa o nível de radiação recebida proporcionalmente (modelo linear limiar), ou seja, não existe nenhum tipo de carga que se possa receber sem que afete os seres em geral, o que vai contra o relatório acima citado.

O mesmo documento estima que até quatro mil crianças receberam doses suficientes para desenvolver câncer de tireóide no dia do acidente. Identificou-se também (de acordo com o mesmo documento) que as pessoas de baixa renda econômica resistiram em sair, mas como o nível de radiação estava acima dos padrões, tais pessoas sofreram grande radiação.

Como observado no relatório de Chernobyl Fórum de Saúde, o impacto sobre a saúde mental de Chernobyl é o maior problema de saúde pública desencadeada pelo acidente até hoje. Sofrimento psíquico decorrente do acidente e suas consequências tem tido um impacto profundo sobre $\mathrm{O}$ comportamento individual e da comunidade populações em áreas afetadas exibem atitudes fortemente negativas na auto-avaliações de saúde e de bem-estar e um forte sentimento de falta de controle sobre suas próprias vidas. Associado a estas percepções é um sentimento exagerado os perigos para a saúde da população exposta a radiação. Os afetados apresentam uma crença generalizada de que as pessoas expostas são de alguma forma condenadas a uma expectativa de vida mais curta. Esse fatalismo também está ligado a uma perda de iniciativa para resolver os problemas de sustentar uma renda e dependência de ajuda do Estado (FORUM DE CHERNOBY, 2005, p. 36 tradução nossa).

Segundo a jornalista, política e escritora Alla Yaroshinskaya pesquisadora sobre o tema, que em sua carreira publicou vários trabalhos e livros sobre Chernobyl e indicada ao prêmio Nobel da paz em 2005, teve acesso aos documentos secretos enquanto ela fazia parte do Supremo Soviético em 1990 quando a URSS estava se desfazendo. Segundo esta autora os documentos comprovam que a alta cúpula do partido modificou deliberadamente os níveis aceitáveis de radiação que uma pessoa pode receber, diminuindo as taxas de pessoas contaminadas. Essa foi uma das decisões macabras que o governo soviético decidiu fazer, os motivos certamente seria a sua permanência no poder, manter o controle sobre as pessoas e a imprensa e diminuir os gastos com o acidente. Segundo Yaroshinskaya além dos materiais radioativos, o reator liberou outro produto que afetou apenas os lideres da URSS à mentira ou como ela cita "a mentira de 82 " fazendo um jogo de palavras com o césio 137.

Um documento que comprova que a sociedade afetada e os órgãos de pesquisa não 
chegaram ao um consenso sobre as mortes e vítimas, foi produzido pelo parlamento Europeu em onze de abril de 2011 com este registro: B5-0325/2001 que trata sobre a segurança nuclear quinze anos depois do acidente. Este documento relata a divergência de opiniões da seguinte forma:

\begin{abstract}
Considerando que, até à data, as consequências do acidente reconhecidas oficialmente se limitam a 33 mortos e a 1800 crianças e adolescentes vítimas de cancro da tiróide; que o relatório 2000 do UNSCEAR sobre esta matéria apenas reforça esta atitude, apesar de este balanço oficial ser veemente $\mathrm{e}$ continuamente contestado pelas vítimas e pelos especialistas e os cientistas ligados a este domínio; que organismos oficiais como a Organização Mundial de Saúde (OMS) e o Serviço das Nações Unidas para a Coordenação dos Assuntos Humanitários têm uma posição muito diferente (PARLAMENTO EUROPEU, 2011, p. 2).
\end{abstract}

É evidente que o trabalho de memória e esquecimento de micro e macro-história está fortemente ligado a este assunto, já que quando o assunto torna-se alvo das atenções, os temas lembrados são apenas o acidente, cidade fantasma, comunismo, erros e etc. Sempre esquecendo-se das pessoas que morreram ou tiveram suas vidas afetadas. $\mathrm{O}$ processo de esquecimento também refere-se aos problemas econômicos. Em 1986 a segunda crise do petróleo e a demanda de energia barata fez com que a URSS suprimisse o reconhecimento de quatro mil mortes, pois era necessário que a opinião pública não interferisse em questões nucleares do país. A questão das pensões também entra no cálculo para não reconhecer essas pessoas como vítimas. O relatório do fórum de Chernobyl reconhece que a radiação pode modificar ou matar.

Interação da radiação ionizante (alfa, beta, gama e outros tipos de radiação) com matéria viva pode danificar as células humanas, causando a morte de alguns e modificando outras. A exposição à radiação ionizante é medida em termos de energia absorvida por unidade de massa, isto é, a dose absorvida. A unidade de dose absorvida é o gray (Gy) (FORUM DE CHERNOBY, 2005, p. 36).

O mesmo relatório aponta que a radiação mais forte foi recebida pelos trabalhadores da usina e pelos bombeiros, já a população não sofreu com uma dose de corpo inteiro, não mais do que o mesmo nível da radiação de fundo. $\mathrm{O}$ impacto socioeconômico reconhecido foi enorme nas regiões europeias mais afetadas, o nível de pessoas principalmente crianças que desenvolveram câncer, de tireoide foi de quatro mil em 2002 (FORUM DE CHERNOBY, 2005).

Outro estudo realizado por 60 pesquisadores a pedido da organização não governamental Greenpeace (2006) aponta que o número de mortes provocadas pelo acidente pode alcançar a marca próxima de cem mil vítimas nos três países mais afetados. O mesmo documento acredita que só na Rússia o número de mortes já alcançou cerca de sessenta mil, e na Belarus e Ucrânia o número é de cento e quarenta mil vítimas, contestado 
pelo relatório da UNO como na seguinte passagem:

Apesar das dificuldades para dimensionar o real número de vítimas, os resultados do relatório do Greenpeace comprovam que as estatísticas oficiais da Agência Internacional de Energia Atômica (AIEA), divulgadas em setembro último e que falam em 4 mil vítimas, subestimam de forma grosseira o número de mortes provocadas pelo acidente, numa atitude desrespeitosa para com as vítimas (GREENPEACE, 2006a).

Quando analisado esse documento na íntegra, identificam-se pontos controvertidos quanto ao número de mortes.

Apesar da seriedade e extensão geográfica documentada da contaminação causada pelo acidente, a totalidade de impactos em ecossistemas, saúde humana, desempenho econômico e estruturas sociais continua desconhecida. Em todos os casos, impactos assim tendem a ser extensos e duradouros (GREENPEACE, 2006b, p. $3)$.

Na pesquisa se leva em conta tudo que afeta a vida das pessoas, e é detalhada os tipos de doenças que as pessoas podem desenvolver, tais com: problemas respiratórios, digestivos, hormonais e diversos tipos de câncer. Além disso, em nenhum outro estudo analisado foi discriminado quais grupos de pessoas ficaram mais suscetíveis a essas doenças.

1.Trabalhadores de limpeza ou 'liquidatários', incluindo civis e militares designados a continuar com suas atividades de limpeza e construir a camada protetora para o reator;

2.Evacuados de territórios perigosamente contaminados num raio de $30 \mathrm{~km}$ ao redor da usina;
3. Residentes dos territórios menos (mas ainda perigosos) contaminados; e

4. Crianças nascidas em famílias de qualquer um dos 3 grupos acima. (GREENPEACE, 2006b, p. 3).

Não se pode analisar o pós-tragédia sem levar em conta todas as estruturas em que essas pessoas vivem atualmente. Não é possível isolar o homem e analisar só sua saúde, sua alimentação, pois cada fator influencia o outro. Essa pesquisa evidencia como os governos escondem juntos com órgãos a real dimensão da tragédia. Essas políticas só causam mais mortes, e menos acesso à verdade e são ligadas ao esquecimento.

Segundo a revista online Exame (26/04/2011) as perdas no acidente já somam 180 bilhões de dólares alcançando $10 \%$ do orçamento anual da Ucrânia, sem contar com as indenizações e auxílios pagos ainda hoje. Recentemente jornais do mundo todo noticiaram que houve desabamento do teto do sarcófago, sendo necessária a construção de uma nova estrutura que cobrirá toda a unidade 4. Seu custo foi estimado em 1,8 bilhões de dólares, sem essa nova contenção o material que está armazenado no interior do prédio pode voltar a expelir radiação para a atmosfera (ver mapa a seguir). 
Mapa - Escala continental do acidente de Chernobyl

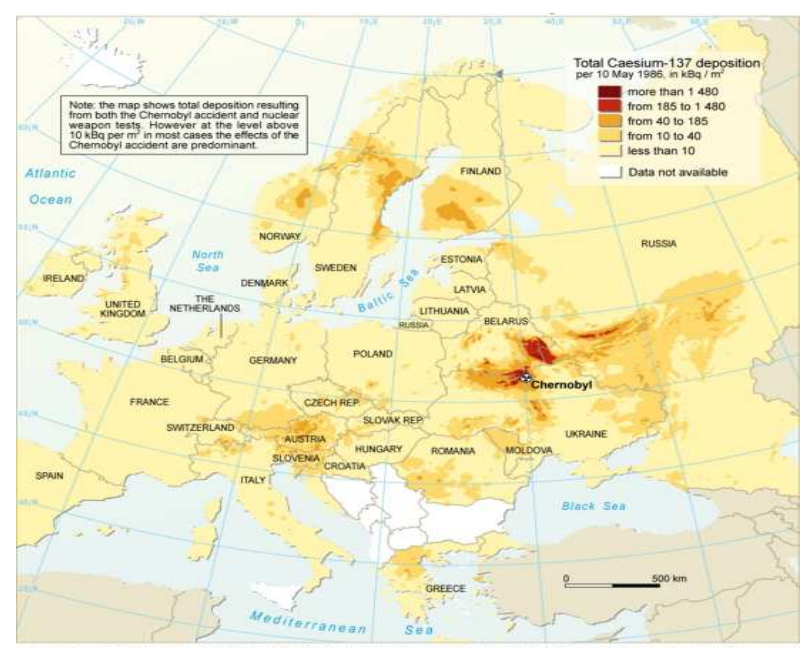

Fonte: GRID ARENDAL (2007)

\section{0 ocidente a um ponto de torna-se uma}

\section{Chernobyl}

A ideologia que possuímos não pode influenciar como olhamos especificamente este acidente, é necessário manter-se o mais neutro possível para não usar os julgamentos de que o outro não é capaz de fazer algo que possamos. Insistentemente os trabalhos produzidos no ocidente visam desqualificar a usina, os engenheiros e os modelos sociais, administrativo e econômico adotados pela URSS.

Assim, como os soviéticos o ocidente superestimou todas as questões nucleares, várias questões técnicas foram tratadas com improviso, ou acabaram utilizado peças alternativas paras situações que não foram planejadas, como no caso da usina de Windscale no Reino Unido:

É evidente que a maior parte da história de Windscale vem sendo entremeada de acidentes e 'desastres que não ocorreram por um triz'. Em outubro dede 1976, detectou-se (por acaso) um vazamento de estrôncio e césio radioativos de um deposito de lixo atômico durante uma obra na usina.Só então percebeu que o vazamento já vinha ocorrendo há uns quatro anos. Enquanto se investigava esse problema, encontrou-se outro grande vazamento em uma estrutura próxima, provavelmente ainda mais antigo que o primeiro, talvez com sete anos de existência (HAWKES et al., 1986, p. 44.)

Em outra passagem, este mesmo o autor aponta a seguinte estatística:

Ao todo, já ocorreram mais de 300 acidentes das mais diversas proporções em Windscale, gerando críticas de parte da indústria nuclear e de outras fontes. Só que nenhum desses acidentes se equipara à serie de ocorrências que teve inicio em 8 de outubro de 1957, quando um físico responsável pelo reator $n^{\circ} 1$ de produção de plutônio cometeu um erro fatal: ligou uma chave antes da hora durante um procedimento de rotina. Como ele não tinha à mão um manual para consulta, e os instrumentos básicos não estivessem marcando o que deveriam, de maneira que ele pudesse obter dados precisos, início-se um incêndio que envolve instantaneamente o reator e permaneceu incontrolável durante 42 horas (HAWKES et al., 1986, p. 44).

A irresponsabilidade das autoridades inglesas chegou a tal ponto que testes com bombas nucleares foram feitas na Austrália. Um destes testes produziu uma enorme nuvem de material radioativo que foi levado pelo vento até uma aldeia aborígene local. Toda a aldeia dos foi contaminada e os moradores começaram a sentir os efeitos da exposição, como se não bastasse pilotos foram enviados para verificar o nível de radiação dessas nuvens sem nenhum tipo de proteção. Para demonstrar como as usinas do 
ocidente não eram tão boas assim, uma comissão do governo norte americano fez uma pesquisa constatando que em 1982 já tinha acontecido cerca de 169 acidentes que poderia ter como causa a fusão do núcleo de reator no território dos EUA. Como última exemplificação e a mais aterrorizante mostra as incoerências no ocidente:

[...] Em um certo reator nuclear, era empregada uma bola de basquete, do tamanho regulamentar, envolta em fita de borracha, para bujonar um tubo. Inevitavelmente, a pressão da água fê-la disparar como uma bala de revolver, causando o vazamento de 53 mil litros de água radioativa. Em outro, um tanque de dejetos com capacidade para $11 \mathrm{mil}$ litros estava ligada a um bebedouro. [...] Relata que certos sistemas de segurança foram inutilizados em decorrência de algumas válvulas e chaves terem sido deixadas em posição errada, às vezes durante semanas seguidas (HAWKES et al., 1986, p. 5253).

É evidente que todos os países desrespeitaram as normas independentes para que finalidade tivesse. As usinas inglesas, norte americanas, francesas ou soviéticas não eram e não são lugares seguros como é vendida a imagem de uma energia limpa e segura.

\section{Considerações finais}

Fica claro que a maioria dos países desrespeitava as normas de segurança. A crendice na hipótese de que nada dará errado torna-se ainda mais perigosa ao tratar de algo que pode exterminar vidas em questão de minutos, isso acontecia não só na URSS. Infelizmente qualquer uma das usinas estava pronta para torna-se uma Chernobyl. Acusar o projeto ou a capacidade dos engenheiros soviéticos é uma clara demonstração na tentativa de desqualificar os pontos positivos que esses homens criaram. Infelizmente o acidente aconteceu, criando munição para os ataques ocidentais. $\mathrm{O}$ que se pode fazer agora é reconhecer que não se deve trabalhar com "amadorismo", pois nesta área o respeito a todas as normas devem ser cumpridas ao pé da letra para que não ocorram novos acidentes nucleares.

O reconhecimento de todas as vítimas, ajudá-las e fazer o possível para que todas possam viver com melhores condições de vida deve ser um compromisso das autoridades dos países envolvidos, pois muitas gerações ainda sentem esse passado que deixa marca e números de mortes não calculadas.

A história como se sabe nunca se repete, pode apenas ter fatos semelhantes. Hoje se vive a sobra de uma nova catástrofe localizada no Japão mais precisamente na usina de Fukushima, por isso deve-se utilizar o que já foi ensinado da forma mais dolorosa para evitar que vidas inocentes paguem por irresponsabilidades de outros.

\section{Referências}

DALAVIA, Vitor. O desastre nuclear de

Chernobyl (26/041986). Disponível em:

$<$ http://xa.yimg.com/kq/groups/17807105/167 0189686/name/O+ACIDENTE+NUCLEAR+ 
mar. 2014.

DISCOVERY CHANEL. O Desastre de

Chernobyl. (Vídeo) diretor Thomas Johnsonr. 2006.

DUPUY, Jean Pierre. A catástrofe de

Chernobyl vinte anos depois. Revista

Estudos Avançados, v. 21, n. 59, p. 243-252,

2007. Disponível em:

<http://www.scielo.br/pdf/ea/v21n59/a18v215

9.pdf>. Acesso em: 5 mar. 2014.

ESTEVES, Victor. Chernobyl - o fato. Texto disponível em:

<http://www.del.ufrj.br/ victor.esteves/Segur anca2013/trabalhosobreChernobyl.pdf>

Acesso em: 4 dez. 2013.

\section{FORUM DE CHERNOBY. O legado de}

Chernobyl: Saúde, Meio Ambiente e Impactos Sócio-Econômicos. Recomendações ao Os governos de Belarus, da Federação

Russa e da Ucrânia - Viena 2003-2005.

Disponível em:

<http://www.iaea.org/Publications/Booklets/C hernobyl/chernobyl.pdf>. Acesso em: 5 maio 2014.

GREENPEACE. Chernobyl death toll grossly underestimated. Disponível em:

<http://www.greenpeace.org/international/en/ news/features/chernobyl-deaths-180406/>.
GREENPEACE. Novo estudo do Greenpeace revela que número de mortes por câncer de Chernobyl pode chegar a 93 mil. 17, abril, 2006a. Disponível em:

$<$ http://www.greenpeace.org/brasil/pt/Noticia s/novo-estudo-do-greenpeace-reve> Acesso em: 24 nov. 2013.

GREENPEACE. The Chernobyl catastrophe consequences on human health. Amsterdam, the Netherlands , 2006b. Disponível em: $<$ http://www.greenpeace.to/publications/chern obyl_health_report.pdf $>$. Acesso em: 5 mar. 2014.

GREENPEACE. Vítimas de Chernobyl. 18, março, 2011. Disponível em:

< http://www.greenpeace.org/brasil/pt/Blog/vti mas-de-chernobyl/blog/33819> . Acesso em: 26 nov. 2013.

GRID ARENDAL. The continental scale of the Chernobyl accident, 2007. Disponível em: <http://www.grida.no/graphicslib/detail/thecontinental-scale-of-the-chernobylaccident_12e3 >. Acesso em: 10 mar. 2014.

GROSS, B., Chernobyl 1 ano depois. Revista Ciência Hoje, v. 6, n. 32, p. 28-37, 1987.

HAWKES. Nigle et al. Chernobyl: o fim do sonho nuclear. São Paulo: José Olympio, 1986.

Acesso em: 13 nov. 2013. 
MEDVEDEV, Zhores. Inov ação \&

Conservadorismo - nova liderança soviética.

Tradução de Lígia Kosin. Revista Novos

Estudos, n. 17, maio, 1987. Disponível em:

<http://novosestudos.uol.com.br/v1/files/uplo ads/contents/51/20080623_inovacao_e_conse rvadorismo.pdf>. Acesso em: 2 mar. 2014.

\section{PARLAMENTO EUROPEU. Proposta de}

resolução do Parlamento Europeu sobre a segurança nuclear 15 anos depois do acidente de Chernobil. 11 abril, 2011. Disponível em: <http://www.europarl.europa.eu/sides/getDoc. do?pubRef=//EP//NONSGML+MOTION+B5-2001-

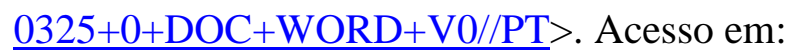
5 mar. 2014.

PASCHOA, Anselmo S. Lições de Tchernobyl - os alimentos importados.

Revista Ciência Hoje, Rio de janeiro, v. 6, n. 32, p.36-37, jun., 1987.

REVISTA EXAME. Perdas pelo acidente de Chernobyl somam US\$ 180 bilhões.

26/04/2011. Disponível em:

$<$ http://exame.abril.com.br/meio-ambiente-eenergia/noticias/perdas-pelo-acidente-dechernobyl-somam-us-180-bilhoes>. Acessado em: 15 de nov. 2013.

REVISTA VEJA. Chernobyl - a explosão vermelha - o reator de uma usina nuclear soviética pega fogo, explode e joga na atmosfera nuvem radioativa que espalha $o$ medo por toda a Europa, n. 922, 7 de maio de
1986. Disponível em:

<http://veja.abril.com.br/idade/em_dia_2001/r eportagens/reportagem_chernobyl.html>.

Acesso em: 10 mar. 2014. 